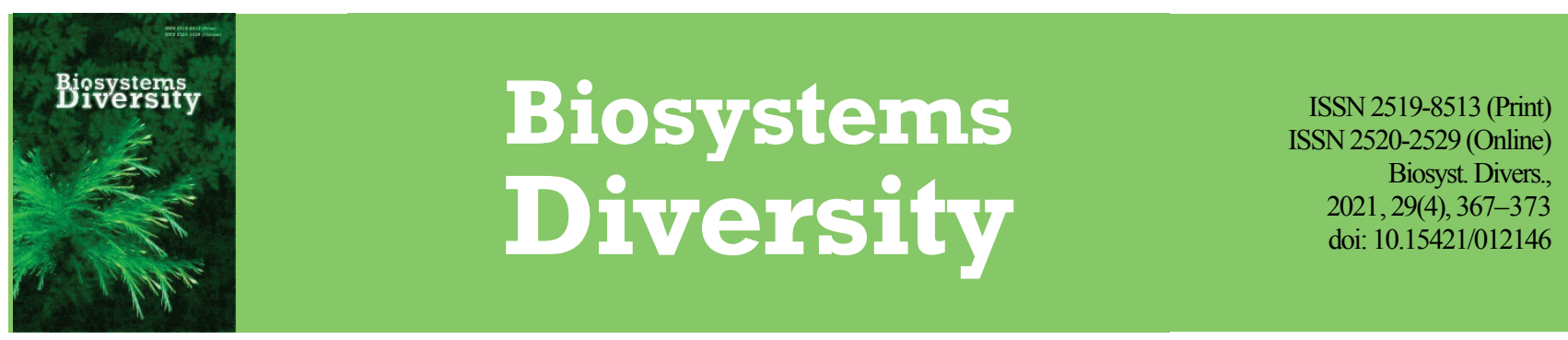

\title{
Physiological responses of orchids to prolonged clinorotation
}

\author{
N. V. Zaimenko*, B. O. Ivanytska*, N. V. Rositska*, N. P. Didyk*, D. Liu**, M. Pyzyk**, J. Slaski*** \\ *M. M. Gryshko National Botanical Garden of the National Academy of Sciences of Ukraine, Kyiv, Ukraine \\ **Jiamusi Universit, Jiamusi, China \\ **United Institute of Modern Technologies (UIoMT), Edmonton, Canada \\ ***Bio-Industrial Services Division, InnoTech Alberta, Vegreville, Canada
}

Article info

Received 01.10.2021

Received in revised form 25.10 .2021

Accepted 27.10.2021

M. M. Gryshko National Botanical

Garden of the National Academy

of Sciences of Ukraine,

Timiryazevska st., 1 ,

Kyiv 01014, Uh:

Tel.: $+38-044-285-41-05$.

E-mail: zaimenkonv@ukr.net

Jiamusi University, Xue Fu st., 148,

Jiamusi, 154007, Heilongïing, China

$\mathrm{Tel} \cdot \mathbf{+}+86-1384-618-18-72$

E-mail: liudejiang2004@163.com

United Institute of Modern

Technologies (UIoMT),

10225 st., 147, Edmonton,

T5N $3 \mathrm{Cl}$, Alberta, Canada

Tel.: + 1-647-687-72-97

E-mail:myron@marenon.com

Bio-Industrial Services Division, InnoTech Alberta,

Hwy 16 A st., 75, Vegreville

Alberta, T9C 1T4, Canada.

Tel.: +1-780-632-84-36.

E-mail:jan.slaski@innotechalberta.ca

\author{
Zaimenko, N. V., Ivanytska, B. O., Rositska, N. V., Didyk, N. P., Liu, D., Pyzyk, M., \& Slaski, J. (2021). Physiological \\ responses of orchids to prolonged clinorotation. Biosystems Diversity, 29(4), 367-373. doi:10.15421/012146
}

Creation of plant-based bioregenerative life support systems is crucial for future long-duration space exploring missions. Microgravity is one of the major stresses affecting plant growth and development under space flight conditions. Search for higher plant genotypes resilient to microgravity as well as revealing of biological features which could be used as markers of such resilience is rather urgently needed. The objective of this study was to analyze physiological and biochemical responses of three orchid species representing different life forms (terrestrial and epiphytic), growth types (monopodial and sympodial) and pathways of $\mathrm{CO}_{2}$ fixation to long-term (24 months) clinorotation which modeled the combined effect of two stress factors: hermetic conditions and microgravity. Three years old meristematic orchids Cypripedium flavum, Angraecum eburneum, Epidendrum radicans, representing different life forms, types of branching shoot system and pathways of $\mathrm{CO}_{2}$ fixation, were used as test-plants. The microgravity was simulated using three-dimensional (3-D) clinostat equipped with two rotation axes placed at right angles (rotation frequency was $3 \mathrm{rpm}$ ) in controlled conditions of air temperature, illumination, air humidity and substrate moisture. The control plants were grown in the similar plastic vessels but not hermetically sealed and without clinorotating in the same environmental conditions. The vital state of the test plants was assessed using characteristics of mineral nutrition, content of photosynthetic pigments, free amino acids, soluble proteins, DNA and RNA, enzymatic and non-enzymatic antioxidants. The results of this study confirmed that orchids grown under simulated microgravity and kept in hermetically-sealed vessels were subjected to oxidative stress, which could be responsible for the observed inhibition of basic physiological processes such as mineral nutrition, metabolism of aminoacids, protein biosynthesis and photosynthesis. Monopodial orchids $C$. flavum and A. eburneum demonstrated better adaptation to prolonged clinorotation as compared to sympodial $E$. radicans. In particular, the latter demonstrated some stimulation of mineral nutrition processes (i.e. $\mathrm{K}, \mathrm{N}, \mathrm{Fe}, \mathrm{Mn}, \mathrm{Zn}$ accumulation), content of photosynthetic pigments, proline and superoxide dismutase activity. Long-lasting clinorotation induced adaptive changes of antioxidant systems in the studied orchids (e.i. increase in carotenoids and proline content and stimulation of superoxide dismutase activity), which helped to maintain the main physiological functions at stable level in the above-mentioned stressful conditions. The following biochemical characteristics in the studied orchids could be considered as markers of resilience to simulated microgravity and hermetic conditions: 1) an increase in the accumulation of non-enzymatic (proline, carotenoids) and enzymatic antioxidants (superoxide dismutase); 2) ability to maintain stable balance of mineral nutrients; 3) increase in the content of photosynthetic pigments; 4) increase in the content of proteinogenic amino acids and soluble proteins; 5) increase in the DNA content or RNA/DNA ratio. Our studies have also demonstrated a correlation between orchid ecomorphological characteristics such as type of branching with their adaptive responses to prolonged clinorotation. We observed no correlation between the studied life form of orchids, ecotype or the pathway of $\mathrm{CO}_{2}$ fixation and their resilience to prolonged clinorotation. This research can be a starting point for studying the relationships between ecomorphological features of various orchids and their resilience to microgravity conditions in the search for biological markers of microgravity tolerance in species of higher plants.

Keywords: Cypripedium flavum; Angraecum eburneum; Epidendrum radicans; clinorotation; adaptive reactions.

\section{Introduction}

Creation of plant-based bioregenerative life support systems is crucial for future long-duration space exploration missions (Brykov et al., 2018; Kiss et al., 2019). Such systems are expected to provide the astronauts' environment with food, $\mathrm{CO}_{2}$ reduction, $\mathrm{O}_{2}$ production, waste recycling and water management. Therefore, since the 1960 -s, there has been a consistent effort to assess the effect of the spaceflight environment upon higher plants' growth, development and productivity (Kiss et al., 2019). Numerous studies were dedicated to the effects of altered gravity and closed environments on the basic plant physiological processes such as growth, development, reproduction, photosynthesis, nutrition etc. (Zheng et al., 2015; Paul et al., 2017). However, until now, the mechanisms underlying plant responses to such outer space variables, as well as the consequences of such alterations on crop productivity, have not been com- pletely elucidated (Zabel et al., 2016). Microgravity was shown to affect the condition of plants, which in turn impedes the physiological transportation of water and solutes, gas exchange processes. Limited gas exchange and root zone hypoxia can result in a reduced uptake and transport of nutrients in plants. Some studies indicate that the stunted growth observed in microgravity can be linked to nutritional issues and that nutrient uptake is altered by the outer space environment (Wolff et al., 2013, 2018).

A number of the studies with selected crop species (lettuce, radish, green onion, carrot etc.) were focused on the possibilities to adjust environmental conditions (e.g., light, temperature, $\mathrm{CO}_{2}$ concentration, humidity, fertilization with mineral nutrients) of the spacecraft's plant growth facilities to optimize the growth and productivity of higher plants (Brykov et al., 2018). The results of these studies demonstrated that the interaction between gravity effects and other environmental factors connected with space flight conditions (such as increased temperature and humidity, $\mathrm{CO}_{2}$ 
concentration due to cultivation in hermetic growth containers) could significantly affect both plant primary and secondary metabolism, influencing accumulation of macronutrients in plant tissues as well as inducing production of phytotoxic phenolic compounds, which could further inhibit growth and development of plants (Khodadad et al., 2020). In those studies, biochemical and physiological characteristics of crops were often evaluated in terms of their growth, development, productivity, nutritional value and storage capacity (Oluwafemi et al., 2019). However, the continuous cultivation of plants in closed ecosystems requires adequate evaluation of their functional state, stability of their associations as well as the capacity of latter to adapt to environmental stress factors (Zabel et al., 2016).

During the last four decades, there were published studies of the possibility of using the self-regulating supply systems of nutrients to provide plants with macro- and micronutrients necessary for their growth and development (Zabel et al., 2016). The advantage of passive supply of necessary micro-supplements for plant growth and development was confirmed (Zaimenko, 1999; Brykov et al., 2018). On the other hand, active systems required sophisticated equipment and could not be compatible with space flight resources. Therefore, there is still the need to develop cost-effective technology for long-term cultivation of plants in sustainable systems.

Another approach implies the need to select plant species genotypes that are resilient to the stressful conditions of space flight. Plants can adapt to extreme environments on Earth, and model plants have been shown to grow and develop through a full lifecycle in microgravity. Until now, only a limited number of plant species have been tested for their sensitivity to microgravity (Zaimenko, 1999; Paul et al., 2017; Zheng et al., 2015). A number of such investigations gave some insight into the physiological mechanisms of adaptive responses of the tested plants to these kind of stresses (Kochubey et al., 2004; Zheng et al., 2015; Moreno-Villanueva et al., 2017). However, more knowledge is needed about the long- term effects of the extraterrestrial environment on plant growth and development.

The objective of our study was to analyze the peculiarities of the physiological and biochemical processes in orchids that have different growth types, life forms and $\mathrm{CO}_{2}$ fixation pathways after 24 months of cultivation in the hermetic vessels, under simulated microgravity.

\section{Materials and methods}

The experiments were conducted at the Department of Allelopathy of the M. M. Gryshko National Botanical Garden of the National Academy of Sciences of Ukraine (Kyiv city, Ukraine). Three year old meristematic orchids of Cypripedium flavum P. F. Hunt \& Summerh., Angraecum eburneum Bory., Epidendrum radicans Lindl., representing different life forms, types of branching and pathways of $\mathrm{CO}_{2}$ fixation (Buyun et al., 2015; Muthukumar \& Shenbagam, 2017) were used as test plants (Table 1).

\section{Table 1}

Ecomorphophysiological characteristics of the orchid test-plants

\begin{tabular}{lcccc}
\hline \multicolumn{1}{c}{ Orchid species } & Life form & $\begin{array}{c}\text { Type of } \\
\text { branching }\end{array}$ & $\begin{array}{c}\mathrm{CO}_{2} \text { fixation } \\
\text { pathway }\end{array}$ & Ecotype \\
\hline $\begin{array}{l}\text { Cypripedium flavum } \\
\begin{array}{l}\text { P.F. Hunt \& Summerh. } \\
\text { Angraecum eburneum Bory. }\end{array}\end{array}$ terrestrial & monophytic & $\mathrm{C}_{3}$ & mesophyte \\
Epidendrum radicans Lindl. & epiphytic & sympodial & $\mathrm{CAM}$ & $\begin{array}{c}\text { xeromeso- } \\
\text { phyte }\end{array}$ \\
\hline
\end{tabular}

Note: $\mathrm{C}_{3}$ - pathway of $\mathrm{CO}_{2}$ assimilation is the most common metabolic pathway for carbon fixation in photosynthesis, which doesn't have photosynthetic adaptations to reduce photorespiration. CAM - (crassulacean acid metabolism) pathway minimizes photorespiration by separating processes of the light-dependent reactions and assimilation of $\mathrm{CO}_{2}$ in the Calvin cycle in time.

The test plants were grown in hermetic plastic (acrylic) vessels under simulated microgravity for 24 months. Each vessel contained one plant of each species. The microgravity was simulated using three-dimensional (3-D) clinostat equipped with two rotation axes placed at right angles (rotation frequency was $3 \mathrm{rpm}$ ) under controlled conditions of air tempera- ture $\left(20-22{ }^{\circ} \mathrm{C}\right)$, illumination (1700 lux), air humidity $(80-83 \%)$ and substrate moisture of $70-75 \%$ of full water-holding capacity. As a substrate, polyacrylonitrile fibres shredded to the size of $5 \mathrm{~mm}$ were used. Before planting the plants, the substrate was watered with Knopp's solution. In 1 litre of water, there were dissolved $1 \mathrm{~g}$ of calcium nitrate, $0.25 \mathrm{~g}$ of potassium phosphate and $0.25 \mathrm{~g}$ of magnesium sulfate, $0.125 \mathrm{~g}$ of potassium chloride, $0.125 \mathrm{~g}$ of iron chloride.

The control plants were grown in similar plastic vessels in airtight conditions but without clinostatting and with no clinorotation in the same environmental parameters of temperature, illumination and substrate moisture. At the end of the experiments, the $\mathrm{CO}_{2}$ concentrations in the hermetic and control vessels were measured and the physiological characteristics of each respective orchid's vital state was measured. The latter included the content of macro- and micronutrients, photosynthetic pigments, free amino acids, soluble proteins, DNA and RNA, protective antioxidants (proline, catalase, superoxide dismutase), and malondialdehyde in the leaves of the test plants.

The concentrations of macro- and micronutrients were determined in the leaves and aerial roots of the test plants. Photosynthetic pigments (chlorophylls $a, b$ and carotenoids) were extracted from the leaves (fully expanded, exposed) of the tested plants at a similar position within each treatment. The optical density was measured with a Specord 200 (Analytik Jena, Germany, 2003) at $665 \mathrm{~nm}$ for chlorophyll a, $649 \mathrm{~nm}$ for chlorophyll $\mathrm{b}$ and $480 \mathrm{~nm}$ for carotenoids. The photosynthetic pigments (chlorophylls $a, b$ and carotenoids) were extracted from freshly collected leaves with dimethylsulfoxide (DMSO) (Wellburn, 1994). The contents of macro- and micronutrients in the leaves and aerial roots of orchids were determined using an inductively coupled plasma spectrometer iCAP 6300 DUO from Thermo Fisher Scientific, USA (2006). Concentrations of nucleic acids in leaves of orchids were determined using the methodology described in (Sadak et al., 2015) and spectrophotometrically with Specord 200. Qualitative and quantitative contents of free amino acids were determined using an amino acid analyzer Hitachi (Ovchinnikov, 1974). The $\mathrm{CO}_{2}$ contents in the hermetically-sealed vessels were measured using $\mathrm{CO}_{2}$-analyzer ( $\mathrm{S} 157-\mathrm{P} \mathrm{CO}_{2}$ Analyser (0-2000 ppm) with gas pump and temperature control, Qubit Systems, Canada, 2019).

Proline content was measured using the method provided by Ábrahám et al. (2010). Leaves $(0.5 \mathrm{~g})$ were extracted with 3\% (w/v) sulphosalicylic and free proline content was measured using ninhydryn reagent. Lipid peroxidation level was assayed in leaf samples as the malondialdehyde content. The malondialdehyde content was determined using the thiobarbituric acid reaction following by colorimetry the absorbance at $532 \mathrm{~nm}$ using the methodology described in Hellmann et al. (2010). An extinction coefficient of $155 \mathrm{mM}^{-1} \mathrm{~cm}^{-1}$ was used to determine the malondialdehyde concentration. Total superoxide dismutase activity was determined by the inhibition of the photochemical reduction of nitroblue tetrazolium by the enzyme using the procedure described by Tang \& Newton (2004). The protein concentration was determined by a modification of the Coomassie Brilliant Blue-based method (Assimakopoulos et al., 2008). Catalase activity was measured using the potassium permanganate titration method (Wang \& Zhan, 2009).

The groups of values were compared by U-criterion MannWhitney. This is a statistical criterion used to assess differences between two independent samples, allows us to identify differences in the parameter value between small samples for $\mathrm{P}<0.05, \mathrm{P}<0.01, \mathrm{P}<0.001$. Quantitative indicators of the content of mineral nutrients in leaves and soil are given as arithmetic mean with standard deviation. The statistical analysis was performed using Statistica 10.0 software (Stat Soft Inc., Tulsa, USA, 2011).

\section{Results}

All the studied orchids demonstrated positive growth and produced high biomass in the hermetically sealed vessels exposed to clinorotating over the period of 24 months. Analysis of the balance of the macro- and micronutrients in the exposed plants, as compared to control, showed some differences in accumulation of macro- $(\mathrm{N}, \mathrm{K})$ and micronutrients (Fe, Mn, Zn) among monopodial (C. flavum, A. eburneum) and sympodial (E. radicans) orchids (Tables 2,3 ). 
Table 2

The contents of macro- and microelements in the leaves of orchids after 24 months of clinorotation as compared to control $(\mathrm{x} \pm \mathrm{SD}, \mathrm{n}=6)$

\begin{tabular}{|c|c|c|c|c|c|c|c|c|c|c|}
\hline \multirow{2}{*}{ Orchid species } & \multirow{2}{*}{ Treatment } & \multicolumn{5}{|c|}{ Macroelements, $\mathrm{g} / \mathrm{kg}$ plant dry weight } & \multicolumn{4}{|c|}{ Microelements, $\mathrm{mg} / \mathrm{kg}$ plant dry weight } \\
\hline & & $\mathrm{N}$ & $\mathrm{P}$ & $\mathrm{K}$ & $\mathrm{Ca}$ & $\mathrm{Mg}$ & $\mathrm{Fe}$ & $\mathrm{Mn}$ & $\mathrm{Cu}$ & $\mathrm{Zn}$ \\
\hline \multirow{2}{*}{ C. flavum } & control & $30.12 \pm 5.51$ & $5.41 \pm 0.92$ & $23.45 \pm 1.87$ & $11.14 \pm 1.98$ & $2.73 \pm 0.36$ & $108.40 \pm 4.95$ & $53.84 \pm 2.47$ & $18.68 \pm 1.54$ & $39.26 \pm 2.23$ \\
\hline & clinorotation & $38.64 \pm 4.32$ & $4.87 \pm 0.65$ & $49.84 \pm 7.41$ & $8.73 \pm 1.72$ & $2.12 \pm 0.44$ & $93.92 \pm 3.34$ & $68.74 \pm 2.63$ & $14.41 \pm 1.22$ & $32.73 \pm 2.74$ \\
\hline \multirow{2}{*}{ A. eburneum } & control & $36.48 \pm 2.91$ & $5.97 \pm 1.32$ & $26.6 \pm 4.42$ & $13.36 \pm 1.31$ & $1.67 \pm 0.32$ & $143.74 \pm 1.77$ & $49.39 \pm 2.18$ & $14.34 \pm 1.24$ & $49.24 \pm 2.01$ \\
\hline & clinorotation & $45.25 \pm 3.72$ & $5.36 \pm 1.11$ & $38.01 \pm 3.82$ & $40.13 \pm 0.72 * *$ & $1.22 \pm 0.26^{* *}$ & $127.31 \pm 2.08$ & $64.87 \pm 3.28$ & $9.84 \pm 0.79$ & $35.82 \pm 1.92$ \\
\hline \multirow{2}{*}{ E. radicans } & control & $34.54 \pm 2.74$ & $7.93 \pm 0.63$ & $42.72 \pm 3.41$ & $9.93 \pm 0.82$ & $2.31 \pm 0.84$ & $84.42 \pm 3.88$ & $92.33 \pm 2.53$ & $21.44 \pm 1.73$ & $33.78 \pm 2.71$ \\
\hline & clinorotation & $24.83 \pm 2.19$ & $5.22 \pm 0.44$ & $14.26 \pm 1.63$ & $4.71 \pm 0.45$ & $2.12 \pm 0.61$ & $75.92 \pm 3.19$ & $63.84 \pm 2.21$ & $19.32 \pm 1.92$ & $30.56 \pm 2.49$ \\
\hline
\end{tabular}

Note: the difference between control and clinorotation is significant at ${ }^{*}-\mathrm{P}<0.05,{ }^{* *}-\mathrm{P}<0.01, * * *-\mathrm{P}<0.001$.

Table 3

The contents of macro- and microelements in the aerial roots of orchids after 24 months of clinorotation as compared to control $(\mathrm{x} \pm \mathrm{SD}, \mathrm{n}=6)$

\begin{tabular}{|c|c|c|c|c|c|c|c|c|c|c|}
\hline \multirow{2}{*}{ Orchid species } & \multirow{2}{*}{ Treatment } & \multicolumn{5}{|c|}{ Macroelements, g/kg plant dry weight } & \multicolumn{4}{|c|}{ Microelements, $\mathrm{mg} / \mathrm{kg}$ plant dry weight } \\
\hline & & $\mathrm{N}$ & $\mathrm{P}$ & $\mathrm{K}$ & $\mathrm{Ca}$ & $\mathrm{Mg}$ & $\mathrm{Fe}$ & $\mathrm{Mn}$ & $\mathrm{Cu}$ & $\mathrm{Zn}$ \\
\hline \multirow{2}{*}{ C. flavum } & control & $12.34 \pm 1.42$ & $3.76 \pm 0.44$ & $25.51 \pm 2.02$ & $9.33 \pm 0.71$ & $3.17 \pm 0.24^{*}$ & $97.54 \pm 2.96$ & $51.32 \pm 3.16$ & $13.61 \pm 1.11$ & $34.93 \pm 2.94$ \\
\hline & clinorotation & $24.44 \pm 1.92 *$ & $3.46 \pm 0.45$ & $30.51 \pm 2.42$ & $8.22 \pm 0.61$ & $1.94 \pm 0.23$ & $75.64 \pm 3.17$ & $62.29 \pm 3.07$ & $10.92 \pm 0.88$ & $25.38 \pm 2.07$ \\
\hline \multirow{2}{*}{ A. eburneum } & control & $29.39 \pm 2.28$ & $3.61 \pm 0.35$ & $20.28 \pm 1.74$ & $7.59 \pm 0.62$ & $2.52 \pm 0.19$ & $132.78 \pm 3.11$ & $45.24 \pm 1.68$ & $11.35 \pm 0.91$ & $41.29 \pm 2.38$ \\
\hline & clinorotation & $33.49 \pm 2.71$ & $3.39 \pm 0.31$ & $24.44 \pm 1.92$ & $4.48 \pm 0.43$ & $1.71 \pm 0.11$ & $115.78 \pm 2.45$ & $57.39 \pm 2.60$ & $8.21 \pm 0.77$ & $29.24 \pm 2.27$ \\
\hline \multirow{2}{*}{ E. radicans } & control & $36.28 \pm 2.91$ & $3.71 \pm 0.29$ & $21.31 \pm 1.69$ & $5.62 \pm 0.51$ & $1.74 \pm 0.09$ & $75.49 \pm 3.15$ & $48.37 \pm 3.95$ & $17.42 \pm 1.41$ & $23.43 \pm 1.87$ \\
\hline & clinorotation & $28.54 \pm 2.31$ & $3.11 \pm 0.23$ & $19.28 \pm 1.64$ & $3.14 \pm 0.32$ & $1.53 \pm 0.12$ & $68.31 \pm 2.57$ & $39.64 \pm 3.22$ & $15.13 \pm 1.23$ & $21.22 \pm 2.04$ \\
\hline
\end{tabular}

Note: see Table 2 .

In particular, the contents of $\mathrm{N}, \mathrm{K}$ and $\mathrm{Mn}$ were increased in monopodial C. flavum and A. eburneum and inhibited in sympodial E. radicans. The content of phosphorus decreased significantly in E. radicans, while C. flavum and A. eburneum showed insignificant variation in this chemical element. On the other hand, the micronutrient content $(\mathrm{Fe}, \mathrm{Cu}, \mathrm{Zn}) \mathrm{de}-$ creased more sharply in monopodial A. eburneum and C. flavum as compared to $E$. radicans after prolonged clinorotation. In the distribution of $\mathrm{Ca}$ and $\mathrm{Mg}$ in leaves, the same tendency towards a decrease in the concentration of these elements was observed in both mono- and sympodial species. The pattern was traced in the tissues of the aerial roots of the experimental plant species. The contents of macro- and microelements in the roots were lower than in the leaves. The most significant differences were observed in $\mathrm{N}, \mathrm{P}, \mathrm{K}$, and $\mathrm{Fe}$ in the tissues of orchid plants; in particular, in monopodial species, their level increased under conditions of clinostation and tightness, while in sympodial species, on the contrary, decreased.

The combined effects of simulated microgravity and hermetic environment contributed to significant changes in the content of the photosynthetic pigments found in the leaves of test plants. In orchids with a monopodial type of branching, which had been exposed to clinorotation, the contents of chlorophylls a and $\mathrm{b}$ increased by 1.6-2.0 times, compared with the control. In the sympodial E. radicans, we observed an opposite tendency (Table 4). Accelerated biosynthesis of photosynthetic pigments in monopodial species of orchids under clinostatic conditions may be associated with insufficient phosphate supply in the presence of incompatible water deficiency, accompanied by the binding of pigments in the protein-lipid complex.

There was an insignificant difference in the quantitative indicators of $\mathrm{CO}_{2}$ content in sealed vessels depending on growing conditions and biological characteristics of plants. Thus, the $\mathrm{CO}_{2}$ content in the cham- ber decreased by 1.3-1.9 times in tightness conditions. The clinorotation did not significantly affect the $\mathrm{CO}_{2}$ concentration. The highest $\mathrm{CO}_{2}$ content in the chamber was observed in plants with the monopodial type of branching of the shoot system, which led to terrestrial life form, namely $C$. flavum. Outside sealed vessels $\mathrm{CO}_{2}$ level was $422 \mathrm{ppmV}$, in the hermetically-sealed vessels without clinorotation $-302 \mathrm{ppmV}$, and in the clinorotated sealed vessels $-318 \mathrm{ppmV}$. For other experimental species, these values were: for A. eburneum - 221 and $235 \mathrm{ppmV}$, and for $E$. radicans -234 and $243 \mathrm{ppmV}$, respectively.

Table 4

Content of photosynthetic pigments in the leaves of orchids after 24 months of clinorotation and in control $(n=6)$

\begin{tabular}{|c|c|c|c|c|}
\hline \multirow[t]{2}{*}{ Species } & \multirow[t]{2}{*}{ Treatment } & \multicolumn{3}{|c|}{$\begin{array}{l}\text { Content of photosynthetic pigments } \\
\text { in the leaves, } \mathrm{mg} / \mathrm{g} \text { fresh weight }\end{array}$} \\
\hline & & chlorophyll a & chlorophyll b & carotenoids \\
\hline \multirow{2}{*}{ C. flavum } & control & $10.44 \pm 1.68$ & $4.72 \pm 0.45$ & $6.71 \pm 0.61$ \\
\hline & clinorotation & $18.92 \pm 1.62 *$ & $8.14 \pm 0.81 *$ & $10.89 \pm 0.78^{* *}$ \\
\hline \multirow{2}{*}{ A. eburneum } & control & $14.42 \pm 0.84$ & $6.81 \pm 0.64$ & $6.93 \pm 0.92$ \\
\hline & clinorotation & $28.41 \pm 2.33^{*}$ & $10.94 \pm 0.82^{*}$ & $13.22 \pm 0.88^{* *}$ \\
\hline \multirow{2}{*}{ E. radicans } & control & $17.33 \pm 0.42$ & $8.91 \pm 0.45$ & $8.79 \pm 0.73$ \\
\hline & clinorotation & $13.51 \pm 1.98$ & $6.84 \pm 0.52$ & $9.23 \pm 0.91$ \\
\hline
\end{tabular}

Note: see Table 2

The clinorotation for 24 months caused different changes in the quantitative and qualitative contents of free amino acids in the leaves and aerial roots of orchids belonging to different types of branching. In monopodial species (C. flavum and A. eburneum), the total content of free amino acids decreased, while in sympodial $E$. radicans, it increased, compared with the control (Tables 5 and 6 ).

Table 5

Quantitative and qualitative content of free amino acids ( $\mu \mathrm{g} / 100 \mathrm{mg}$ of fresh weight) and soluble proteins (SP) ( $\mu \mathrm{g} / \mathrm{g}$ of fresh weight) in leaves of orchids after 24 months of clinorotation as compared to control $(n=6)$

\begin{tabular}{|c|c|c|c|c|c|c|}
\hline \multirow{2}{*}{ Aminoacids } & \multicolumn{2}{|c|}{ C.flavum } & \multicolumn{2}{|c|}{ A. eburneum } & \multicolumn{2}{|c|}{ E. radicans } \\
\hline & control & clinorotation & control & clinorotation & control & clinorotation \\
\hline Asparagine & $1.03 \pm 0.02$ & $0.87 \pm 0.07$ & $1.48 \pm 0.09$ & $1.26 \pm 0.03$ & $2.31 \pm 0.52$ & $5.86 \pm 0.14^{*}$ \\
\hline Threonine & $0.98 \pm 0.10$ & $0.17 \pm 0.02$ & $0.51 \pm 0.07$ & $0.19 \pm 0.01$ & $0.81 \pm 0.07$ & $0.33 \pm 0.02$ \\
\hline Serine & $0.44 \pm 0.05$ & $0.15 \pm 0.01$ & $0.19 \pm 0.04$ & $0.27 \pm 0.06$ & $0.96 \pm 0.11$ & $1.19 \pm 0.04$ \\
\hline Glutamic acid & $1.85 \pm 0.31$ & $0.26 \pm 0.07$ & $3.07 \pm 0.01$ & $0.43 \pm 0.09$ & $5.37 \pm 0.05$ & $0.86 \pm 0.08$ \\
\hline Histidine & $2.41 \pm 0.03$ & $1.16 \pm 0.10$ & $3.97 \pm 0.02$ & $2.15 \pm 0.14$ & $1.04 \pm 0.04$ & $0.12 \pm 0.03$ \\
\hline Lysine & $0.17 \pm 0.01$ & $0.04 \pm 0.01$ & $0.24 \pm 0.01$ & $0.05 \pm 0.01$ & $0.11 \pm 0.06$ & $0.05 \pm 0.01$ \\
\hline Arginine & $42.83 \pm 2.57 * *$ & $2.37 \pm 1.78$ & $49.62 \pm 1.05^{*}$ & $19.41 \pm 1.01$ & $15.37 \pm 1.04$ & $55.64 \pm 1.25^{* *}$ \\
\hline Tyrosine & $1.35 \pm 0.07$ & $1.48 \pm 0.11$ & $2.18 \pm 0.11$ & $1.45 \pm 0.13$ & $1.46 \pm 0.09$ & $1.18 \pm 0.10$ \\
\hline Phenylalanine & $1.07 \pm 0.02$ & $2.21 \pm 0.13$ & $0.86 \pm 0.08$ & $1.73 \pm 0.11$ & $0.38 \pm 0.07$ & $1.14 \pm 0.07$ \\
\hline Glycine & $0.05 \pm 0.01$ & $1.03 \pm 0.01$ & $0.09 \pm 0.01$ & $1.11 \pm 0.04$ & $0.21 \pm 0.03$ & $6.66 \pm 0.12 *$ \\
\hline Total & $52.18 \pm 3.19$ & $9.74 \pm 2.31$ & $62.21 \pm 2.21$ & $28.05 \pm 1.63$ & $28.02 \pm 2.08$ & $73.03 \pm 1.86$ \\
\hline SP & $47.73 \pm 2.03$ & $50.93 \pm 1.15$ & $51.80 \pm 1.22$ & $52.93 \pm 1.84$ & $50.60 \pm 1.35$ & $40.04 \pm 1.04$ \\
\hline
\end{tabular}

Note: see Table 2. 
Table 6

Quantitative and qualitative content of free amino acids ( $\mu \mathrm{g} / 100 \mathrm{mg}$ of fresh weight) and soluble proteins (SP) ( $\mu \mathrm{g} / \mathrm{g}$ of fresh weight) in aerial roots of orchids after 24 months of clinorotation as compared to control $(n=6)$

\begin{tabular}{lccccc}
\hline \multirow{2}{*}{ Aminoacids } & \multicolumn{2}{c}{ C.flavum } & \multicolumn{2}{c}{ A. eburneum } \\
\cline { 2 - 6 } & control & clinorotation & control & clinorotation & control \\
\hline Asparagine & $0.67 \pm 0.07$ & $0.57 \pm 0.08$ & $2.97 \pm 0.03$ & $0.81 \pm 0.06$ & $0.11 \pm 0.04$ \\
Threonine & $0.31 \pm 0.11$ & $0.11 \pm 0.03$ & $18.36 \pm 1.19^{* *}$ & $0.47 \pm 0.02$ & $0.24 \pm 0.07$ \\
Serine & $0.54 \pm 0.06$ & $0.15 \pm 0.01$ & $0.21 \pm 0.07$ & $0.27 \pm 0.06$ & $1.88 \pm 0.11$ \\
Glutamic acid & $6.28 \pm 0.08^{* *}$ & $0.14 \pm 0.03$ & $15.33 \pm 0.12^{* *}$ & $0.17 \pm 0.05$ & $0.73 \pm 0.02$ \\
Histidine & $0.79 \pm 0.03$ & $0.94 \pm 0.06$ & $0.83 \pm 0.13$ & $1.96 \pm 0.04$ & $2.75 \pm 0.06^{*}$ \\
Lysine & $0.25 \pm 0.04$ & $0.11 \pm 0.01$ & $2.38 \pm 0.17^{*}$ & $0.15 \pm 0.01$ & 0.17 \\
Arginine & $47.72 \pm 1.87^{* *}$ & $21.83 \pm 1.78$ & $83.56 \pm 4.15^{* *}$ & $23.51 \pm 3.14$ & $27.61 \pm 0.09$ \\
Tyrosine & $1.37 \pm 0.14$ & $1.48 \pm 0.11$ & $7.19 \pm 0.12^{*}$ & $1.45 \pm 0.13$ & $0.12 \pm 0.03$ \\
Phenylalanine & $0.14 \pm 0.19$ & $2.21 \pm 0.13$ & $0.24 \pm 0.09$ & $1.73 \pm 0.11$ & $0.13 \pm 0.01$ \\
Glycine & $58.34 \pm 0.09$ & $34.19 \pm 6.78$ & $1.83 \pm 0.12$ & $0.68 \pm 0.03$ & $0.12 \pm 0.04$ \\
Total & $116.41 \pm 2.68$ & $61.73 \pm 9.02$ & $132.90 \pm 6.19$ & $31.20 \pm 3.65$ & $0.17 \pm 0.05$ \\
\hline
\end{tabular}

Note: see Table 2 .

Decrease in the level of histidine in the leaves of experimental orchid species indicates impaired phosphate metabolism. At the same time, increase in the concentration of aspartic acid in the organs of a sympodial species indicates ageing of plants, and decrease in its level in the tissues of monopodial species indicates disorder of nitrogen metabolism. Decrease in the concentration of glutamic acid in leaves under conditions of clinostation is associated with inhibition of the biosynthesis of photosynthetic pigments. Noteworthy is significant increase in the arginine content in the leaves and aerial roots of E. radicans, which indicates low supply of phosphorus to plants. At the same time, higher total content of free amino acids in the tissues of sympodial species can be considered as an adaptive response of the plant organism to change in the water regime in microgravity conditions. For the soluble proteins, the opposite tendency was observed.

The quantitative content of nucleic acids in the leaves differed significantly in the tested orchids (Table 7). Epiphytic A. eburneum and E. radicans had greater total nucleic acid content and lower RNA/DNA ratio compared to terrestrial species $C$. flavum. Orchids with different types of branching and life forms responded differently to prolonged clinorotation. In terrestrial monopodial C. flavum, exposed to clinorotation, the DNA content increased, while RNA content did not demonstrate any significant changes as compared to control. In epiphytic monopodial A. eburneum, the DNA content did not change, while RNA content decreased significantly in clinorotation. In epiphytic sympodial $E$. radicans, both abovementioned characteristics were reduced noticeably under prolonged clinorotation as compared to the control. Epiphytic sympodial E. radicans demonstrated the highest susceptibility to stresses imposed by prolonged clinorotation. The total RNA content was more sensitive to the studied stress factors than DNA. No significant correlations were found between the tested species' resilience of aminoacids and protein metabolism in the conditions of prolonged clinorotation and their life form (terrestrial or epiphytic), the pathway of $\mathrm{CO}_{2}$ fixation or ecotype. Terrestrial monopodial C. flavum demonstrated the highest indexes of antioxidant enzymes' (catalase and superoxide dismutase) activities with and without exposure to clinorotation. The proline content in the leaves of C. flavum was also high as compared to E. radicans, but somewhat lower than in A. eburneum (Table 8). E. radicans had the lowest index of catalase activity and proline content, though lipid peroxidation levels (malondialdehyde index) was relatively high.

\section{Table 7}

The contents of nucleic acids in leaves of orchids after 24 months of clinorotation and in the control $(x \pm S D, n=6)$

\begin{tabular}{llcc}
\hline Species & Treatment & $\begin{array}{c}\text { DNA content, } \\
\text { mg of phosphorus } \\
\text { per 1 g of raw weight }\end{array}$ & $\begin{array}{c}\text { RNA content, } \\
\text { mg of phosphorus } \\
\text { per 1 g of raw weight }\end{array}$ \\
\hline \multirow{2}{*}{ C. flavum } & control & $0.250 \pm 0.011$ & $1.211 \pm 0.116$ \\
A. eburneum & clinorotation & $0.274 \pm 0.013$ & $1.180 \pm 0.073$ \\
& control & $0.418 \pm 0.099$ & $4.241 \pm 0.956^{*}$ \\
E. radicans & clinorotation & $0.395 \pm 0.110$ & $1.722 \pm 0.705$ \\
& control & $3.835 \pm 0.494^{*}$ & $1.944 \pm 0.351$ \\
\hline
\end{tabular}

Note: see Table 2 .

Clinorotation lasting 24 moths caused significant changes in the studied characteristics of the antioxidant systems performance in all studied orchids. Monopdial C. flavum and A. eburneum demonstrated increases in proline content, superoxide dismutase activity and reduction in catalase activity under prolonged clinorotation. At the same time, sympodial $E$. radicans demonstrated the different tendency: changes in proline content were insignificant, while catalase activity and malondialdehyde content increased significantly, but superoxide dismutase activity reduced.

Table 8

The characteristics of antioxidant protective systems in leaves of orchids after 24 months of clinorotation as compared to control $(x \pm S D, n=6)$

\begin{tabular}{|c|c|c|c|c|c|}
\hline Species & Treatment & Proline content, $\mu \mathrm{g} / \mathrm{g} \mathrm{FW}$ & $\begin{array}{c}\text { Catalase activity, } \mathrm{mM} \mathrm{H}_{2} \mathrm{O}_{2} / \mathrm{min} \\
\text { per } 1 \mathrm{~g} \text { of fresh weight }\end{array}$ & Malondialdehyde $\mathrm{mcM} / \mathrm{mL}$ & 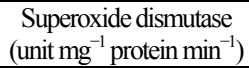 \\
\hline \multirow{2}{*}{ C. flavum } & control & $86.19 \pm 1.48$ & $11.05 \pm 1.56$ & $5.25 \pm 1.22$ & $6.36 \pm 0.98$ \\
\hline & clinorotation & $97.76 \pm 1.81$ & $6.80 \pm 1.09$ & $6.37 \pm 1.18$ & $7.29 \pm 0.99$ \\
\hline \multirow{2}{*}{ A. eburneum } & control & $96.85 \pm 1.53$ & $4.25 \pm 1.05$ & $3.98 \pm 0.64$ & $0.18 \pm 0.06$ \\
\hline & clinorotation & $107.45 \pm 1.81$ & $2.55 \pm 0.81$ & $6.85 \pm 0.81^{*}$ & $0.42 \pm 0.08$ \\
\hline \multirow{2}{*}{ E. radicans } & control & $19.42 \pm 1.12$ & $3.40 \pm 0.55$ & $5.59 \pm 0.44$ & $6.14 \pm 0.88^{*}$ \\
\hline & clinorotation & $18.82 \pm 1.55$ & $6.80 \pm 1.07^{*}$ & $9.54 \pm 0.49$ & $1.25 \pm 0.54$ \\
\hline
\end{tabular}

Note: see Table 2 .

\section{Discussion}

Prolonged clinorotation is known to cause imbalance in mineral nutrition in higher plants (Wolff et al., 2013, 2018; Zabel et al., 2016). Therefore, simulating the specific conditions of a spacecraft requires a special approach that takes into account many environmental factors (the content and characteristics of soil substitutes, humidity, temperature and light) that determine the availability of macro- and micronutrients for plants (Wolff et al., 2013, 2018; Efimov, 2020; Khapugin, 2020; Khodadad et al., 2020; Kirillova \& Kirillov, 2021). Our previous studies revealed increases in the contents of phosphorus, calcium, potassium and manganese in the vegetative organs of terrestrial orchids after 3 months of clinorotation (Zaimenko, 1999). At the same time, the concentration of magnesium in the tissues of all tested plants decreased, while the iron content remained unchanged. Longer clinorotation (for 6 and 12 months) resulted in a sharp decrease in the levels of macronutrients irrespective of the growth type or organs tested (leaves and aerial roots), indicating inhibition of mineral nutrition processes (Cherevchenko et al., 2000). Therefore, we concluded that prolongation of the clinorotation period reduced the capacity of the studied orchids to compensate for negative effects of the simulated microgravity. 
The results of our present study suggest that prolonged clinorotation (24 months) could induce some adaptations of mineral nutrition processes, stimulating accumulation of specific macro- and micronutrients (i.e. K, N, $\mathrm{Fe}, \mathrm{Mn}, \mathrm{Zn}$ ) in monopodial plant species $C$. flavum and A. eburneum. The contents of other important macronutrients (i.e. phosphorus and calcium) did not decrease as sharply as in sympodial E. radicans. Plants of this orchid species demonstrated the significantly lower adaptive potential of its mineral nutrition processes to prolonged clinorotation in the present study.

The maintenance of high photosynthetic rate is needed to optimize $\mathrm{O}_{2}$ production and $\mathrm{CO}_{2}$ removal from bioregenerative life support systems. Photosynthesis is the main metabolic process that provides the formation of plant biomass. The performance of photosynthesis depends on the content of the photosynthetic pigments, their composition and ratio. Microgravity, as any other environmental stress factor, produced an inhibiting effect on photosynthetic function (Zhao et al., 2002; Kochubey et al., 2004; Jiao et al., 2004). Although physiological mechanisms of this phenomenon are not yet clear, it has been recently suggested that the structural and physiological changes in the photosynthetic apparatus under microgravity conditions resulted from indirect effects such as starch accumulation due to the delayed long-distance transport of photosynthetic metabolites (Kochubey et al., 2004).

The results of our study show a positive correlation between the increase in the respective levels of nitrogen and manganese and photosynthetic pigment content in the leaves and aerial roots in both the monopodial $C$. flavum and A. eburneum. Recently published data indicates a close correlation between the contents of leaf chlorophyll and these specific mineral nutrients in higher plants tissues (Gholizadeh et al., 2017).

Clinorotation for 24 months also stimulated accumulation of carotenoids in leaves of $C$. flavum and A. eburneum with monopodial type of branching. At the same time, in sympodial $E$. radicans, clinorotation did not cause any significant change in carotenoids content. Carotenoids and chlorophyll b play a major role in the protection of photosynthetic systems against photooxidative processes. These are efficient antioxidants, scavenging singlet molecular oxygen and peroxyl radicals (McElroy \& Kopsell, 2009). Therefore, the content of carotenoids is sensitive to the influence of abiotic and biotic stress factors and the ratio of these pigments on the content of chlorophylls a and b is a marker of plant stress. In our study, decrease in chlorophylls content and the chlorophylls/carotenoids ratio in the leaves of $E$. radicans exposed to clinorotation, indicated stress or damage of the photosynthetic apparatus; this, in turn, would impact on the growth, productivity and tolerance to other stressful environmental factors.

Species of higher plants were shown to differ significantly in their ability to maintain the efficiency of photosynthesis process under microgravity conditions (Zhao et al., 2002; Stutte et al., 2006). In particular, the same conditions of clinorotation caused almost 2-fold reduction in chlorophylls content in strawberries (Fragaria $\times$ ananassa Duchesne), but stimulated accumulation of these pigments in carnations (Dianthus caryophyllus L.) seedlings (Zhao et al., 2002). In another study (Tay \& Yam, 2019), plasticity in the pathway of $\mathrm{CO}_{2}$ fixation viz. occurrence of CAM metabolism in both $\mathrm{C}_{3}$ and CAM orchids as an adaptation of photosynthetic apparatus to environmental stress factors was demonstrated. The studies revealed that some orchids that fix carbon primarily through the $\mathrm{C}_{3}$ pathway might be $\mathrm{C}_{3}$-CAM intermediate species that have varying degrees of CAM expression, depending on environmental conditions (Tay \& Yam, 2019). It is evident that more work needs to be done to better understand regulation of this CAM activity by clinorotation.

Amino acids are essential components in plant primary metabolism and play a central role in a wide variety of plant physiological processes. Moreover, amino acids serve as precursors for numerous plant secondary metabolites that perform critical functions such as signaling, defense, interactions with other organisms, and photoprotection. Many plant studies have demonstrated accumulation of free amino acids, especially proline, in response to both abiotic and biotic stresses (Pratelli \& Pilot, 2014).

The increase in soluble amino-N (especially the content of free amino acids) is frequently related to protein degradation or inhibition of protein synthesis. The observed increase in the total content of free aminoacids and decrease in soluble proteins in sympodial species $E$. radicans under clinorotation confirmed this assumption. In monopodial orchids, an oppo- site tendency was observed. Prolonged clinorotation caused a decrease in the total content of free amino acids and a slight increase in soluble proteins. In our present investigation, the increase in soluble protein content in the above-mentioned orchid species is likely due to improved growth and adaptive potential as a result of adaptation to prolonged clinorotation. The increase in the levels of histidine and phenylalanine in the leaves of C.flavum and A. eburneum indicated intensification of the growth process. This observed increase in accumulation provides evidence of the amelioration of nitrogen and potassium metabolism in the tested orchids (Wyszkowski, 1996).

The increase in the concentration of free amino acids in the leaves of $E$. radicans also indicated the intensification of stress conditions and the inhibition of some metabolic processes. In particular, arginine accumulation observed in the leaves of $E$. radicans indicated a slowdown in growth processes and inhibition of oxidative phosphorylation. Arginine also serves as the precursor of polyamines, which acts as a reactive oxygen species (ROS)-scavenger as well as membrane protectors in stress tolerance.

Microgravity is known to pose a threat to the DNA and RNA integrity of living organisms, directly or indirectly, through the production of free radicals. Although organisms have evolved strategies to deal with such damage, microgravity can impede DNA repair, resulting in severe DNA lesions (Moreno-Villanueva et al., 2017). The RNA/DNA ratio is indicative of an orchid species adaptation to a terrestrial habitat (Cherevchenko et al., 2020). In our study, the RNA/DNA ratio of the terrestrial species C. flavum was 4.84, which was significantly higher than such of epiphytic orchids A. eburneum (2.72) and E. radicans (0.51). RNA/DNA ratio is a key indicator of the cell biosynthetic activity, which reflects growth processes and responses to environmental stress factors. In particular, chronic stress is reflected in RNA/DNA ratio. In our study, prolonged clinorotation significantly reduced the RNA/DNA ratio in all studied orchids. The inhibiting effect of clinorotation on plants is often explained as due to damage of the protective antioxidant systems (Moreno-Villanueva et al., 2017). Increasing the activities and levels of antioxidant enzymes and metabolites is recognized to be the principal biochemical adaptive reaction of the plants to any kind of environmental stress (Zaimenko et al., 2018).

In our study the combined effect of simulated microgravity and hermetic conditions caused drastic reduction in most of the parameters characterizing enzymatic and non-enzymatic activity in antioxidant systems, while the malondialdehyde content increased in all orchids studied. Malondialdehyde is a breakdown product of peroxidized polyunsaturated fatty acids in plant membranes, indicative of lipid peroxidation levels (Weber et al., 2004), a major damaging effect of ROS. This index is a widely used marker of oxidative lipid injury caused by environmental stress (Yang et al., 2018). The most drastic (almost two-fold) increase in malondialdehyde index was observed in E. radicans, which demonstrated the lowest adaptability to clinorotation. This increase was accompanied with 5-fold reduction of superoxide dismutase activity and 2-fold increase in catalase activity. The both enzymes are crucial reactive oxygen species (ROS) scavengers eliminating superoxide and hydrogen peroxide species in the cell cytoplasm (Batiha et al., 2020; Soliman et al., 2020). Increased catalase activity protects membrane structure and functioning, leading to better plant performance under stressful conditions (Zaimenko et al., 2016, 2018). Superoxide dismutase is one of the most effective components of the antioxidant defense system in plant cells against stresses. Superoxide dismutase in plants participates in several physiological phenomena, including the elimination of $\mathrm{H}_{2} \mathrm{O}_{2}$, toxic oxidation of reducers, biosynthesis and degradation of lignin in cell walls, enzyme catabolism, injury, pathogenic or insect attack and some respiratory processes (Firmansyah \& Argosubekti, 2020). The superoxide dismutase is the first enzymatic barrier against the harmful effects of oxidative stress, converting the $\mathrm{O}_{2}$ into $\mathrm{H}_{2} \mathrm{O}_{2}$ (Alscher et al., 2002). In parallel, the catalase reduces the $\mathrm{H}_{2} \mathrm{O}_{2}$ to $\mathrm{H}_{2} \mathrm{O}$ and $\mathrm{O}_{2}$, preventing the generation of more reactive radicals such as $\mathrm{OH}^{\cdot}$ (Kibinza et al., 2011). Catalase and superoxide dismutase are the most efficient enzymes of antioxidant metabolism, since their combined actions convert hazardous molecules into $\mathrm{H}_{2} \mathrm{O}$ and $\mathrm{O}_{2}$, avoiding damage to cellular components (Scandalios, 1993). This study detected a negative correlation between enzyme activities of superoxide dismutase and catalase in the tested orchids. 
The highest proline content was characteristic for A. eburneum, suggesting an important role for non-enzymatic antioxidants in confronting environmental stress conditions in this species. After long-term exposure to simulated microgravity, proline content in the leaves of A. eburneum increased significantly, a confirmation of the participation of this metabolite in adaptation of orchids to the studied stress factor. The opposite results were obtained for enzymatic antioxidants in A. eburneum tissues.

Proline is an important amino acid that protects plants against different stresses such as drought, salinity, freezing, heavy metal toxicity (Sharma \& Dietz, 2009), plant pathogenic interactions (Fabro et al., 2004) etc. through its active involvement in osmoregulation and antioxidant defense (Abdul et al., 2009). The literature data show that proline metabolism is regulated by abiotic stress and indicates that the accumulation of stress-induced proline is an adaptive response. It is difficult to answer how the proline contributes to the stress tolerance of the plant, the metabolic regulation that causes proline accumulation in high amounts, and whether it is beneficial for plants. The amount of free proline slightly increased in A. eburneum and notably in C. flavum, but decreased in E. radicans, compared with the control plant.

This tendency confirmed the better adaptive potential of $C$. flavum to environment stresses compared with the other tested orchids. This fact indicated lower potential of the tested antioxidants of $E$. radicans to confront damaging effects of microgravity. This tendency correlates with the above-mentioned results in our analysis of the other physiological characteristics.

Under stress, higher concentrations of malondialdehyde are indicative of cellular damage in the plant and increases in the activity of antioxidant enzymes act as a defense against such stress ( $\mathrm{Li}$ et al., 2015).The malondialdehyde content observed in this work under control conditions indicated that the plants were under oxidative stress.

\section{Conclusions}

Responses of plant species to simulated microgravity are known to vary greatly depending on the growth phase, taxonomic position and the duration of microgravity conditions. Our studies demonstrated that longlasting (24 months) clinorotation induced adaptive responses of antioxidant systems in the studied orchids, helping to maintain stable growth and development under the above-mentioned stressful conditions.

The results of this study confirmed that orchids grown under simulated microgravity and kept in the hermetically-sealed vessels were subjected to oxidative stress, which could be responsible for the observed inhibition of the basic physiological processes such as growth, mineral nutrition and photosynthesis. The monopodial epiphytic orchid species, which demonstrated better adaptive capacity of their antioxidant systems, had reduced damage to the physiological processes.

To summarize the following physiological changes indicate adaptation to microgravity and hermetic conditions in higher plants: 1) an increase in the accumulation of non-enzymatic and (proline, carotenoids) and enzymatic (catalase, superoxide dismutase) antioxidants; 2) ability to maintain stable balance of mineral nutrients; 3 ) increase in the content of photosynthetic pigments; 4) increase in content of proteinogenic amino acids and soluble proteins; 5) increase in RNA/DNA ratio.

Our studies also demonstrated a relation between ecomorphological characteristics of orchids, such as type of branching, life form and their adaptive responses to prolonged clinorotation. No correlation between the studied life forms of orchids, ecotype or the pathway of $\mathrm{CO}_{2}$ fixation and their resilience to prolonged clinorotation were found. This research can be a starting point to study the relationships between ecomorphological features of orchid species and their resilience to microgravity conditions in the search for biological markers of microgravity tolerance in species of higher plants.

\section{References}

Ábrahám, E., Cabassa, C., Erdei, L., \& Szabados, L. (2010). Methods for determination of proline in plants. Methods in Molecular Biology, 639, 317-331.

Alscher, R., Erturk, N., \& Heath, L. S. (2002). Role of superoxide dismutase (SODs) in controlling oxidative stress in plants. Journal of Experimental Botany, 53(372), 1331-1341.
Assimakopoulos, S. F., Mavrakis, A. G., Grintzalis, K., Papapostolou, I., Zervoudakis, G., Konstantinou, D., Chroni, E., Vagianos, C. E., \& Georgiou, C. (2008). Superoxide radical formation in diverse organs of rats with experimentally induced obstructive jaundice. Redox Report, 13(4), 179-184.

Batiha, G. E. S., Beshbishy, A. M., Adeyemi, O. S., Nadwa, E. H., Rashwan, E., Kadry, M., Alkazmi, L. M., Elkelish, A. A., \& Igarashi, I. (2020). Phytochemical screening and antiprotozoal effects of the methanolic Berberis vulgaris and acetonic Rhuscoriaria extracts. Molecules, 25(3), 550.

Brykov, V., Kovalenko, E. Y., \& Ivanytska, B. A. (2018). Microcosm as a perspective model for biological experiment at nanosatellite. Space Science and Technology, 24(2), 55-59.

Buyun, L., Cherevchenko, T., Kovalska, L., \& Ivannikov, R. (2015). Reproductive biology of Angraecum eburneum subsp. superbum (Orchidaceae) under glasshouse conditions. Environmental and Experimental Biology, 13, 33-39.

Cherevchenko, T. M., Zaimenko, N. V., \& Kharitonova, I. P. (2000). Growth and contents of some assimilates inleaves of orchids influenced by the long clinostation. Ukrayinsky Botanichny Zhurnal, 56(1), 83-88 (in Ukrainian).

Cherevchenko, T. M., Zaimenko, N. V., \& Martynenko, E. I. (2000). Biokhimichni osoblyvosti epifitnykh ta nazemnykh orkhidey [Biochemical features of epiphytic and terrestrial orchids]. Fisiologiya i Biokhimiya Kulturnykh Rasteniy, 32(2), 121-127 (in Ukrainian).

Efimov, P. G. (2020). Orchids of Russia: Annotated checklist and geographic distribution. Nature Conservation Research, 5(Suppl. 1), 1-18.

Fabro, G., Kovacs, I., Pavet, V., Szabados, L., \& Alvarez, M. E. (2004). Proline accumulation and AtP5CS2 gene activation are induced by plant pathogen incompatible interactions in Arabidopsis. Molecular Plant-Microbe Interactions Journal, 17, 343-350.

Firmansyah, \& Argosubekti, N. (2020). A review of heat stress signaling in plants. IOP Conference Series: Earth and Environmental Science, 484, 012041.

Gholizadeh, A., Saberioon, M., Borůvka L., Wayayok, A., Amin, M., \& Soom, M. (2017). Leaf chlorophyll and nitrogen dynamics and their relationship to lowland rice yield for site-specific paddy management. Information Processing in Agriculture, 4(4), 259-268.

Hellmann, H., Funck, D., Rentsch, D., \& Frommer, W. B. (2000). Hypersensitivity of an Arabidopsis sugar signaling mutant toward exogenous proline application. Plant Physiology, 122(2), 779-789.

Hiscox, J. D., \& Israelstam, C. F. (1979). A method for the extraction of chlorophyll from leaf tissue without maceration. Canadian Journal of Botany, 57, 1332-1334.

Jaleel, C. A., Manivannan, P., Wahid, A., Farooq, M., Al-Juburi, H. J., Somasundaram, R., \& Panneerselvam, R. (2009). Drought stress in plants: A review on morphological characteristics and pigments composition. International Journal of Agriculture and Biology, 11(1), 100-105.

Jiao, S., Hilaire, E., Paulsen, A. Q., \& Guikema, J. A. (2004). Brassica rapa plants adapted to microgravity with reduced photosystem I and its photochemical activity. Physiologia Plantarum, 122(2), 281-290.

Khapugin, A. A. (2020). A global systematic review on orchid data in protected areas. Nature Conservation Research, 5(Suppl. 1), 19-33.

Khodadad, C. L., Hummerick, M. E., Spencer, L. E., Dixit, A. R., Richards, J. T., Romeyn, M. W., Smith, T. M., Wheeler, R. M., \& Massa, G. D. (2020). Microbiological and nutritional analysis of lettuce crops grown on the International Space Station. Frontiers in Plant Science, 11, 199.

Kibinza, S., Bazin, J., Bailly, C., Farrant, J. M., Corbineau, F., \& El-MaaroufBouteau, H. (2011). Catalase is a key enzyme in seed recovery from ageing during priming. Plant Science, 181(3), 309-315.

Kirillova, I. A., \& Kirillov, D. V. (2021). Reproductive success of orchids at the northem border of their distribution areas (North-East of European Russia). Nature Conservation Research, 6(1), 17-27.

Kiss J. Z., Wolverton, C., Wyatt, S. E., Hasenstein, K. H., \& van Loon, J. (2019). Comparison of microgravity analogs to spaceflight in studies of plant growth and development. Frontiers in Plant Science, 10, 1577.

Kochubey, S. M., Adamchuk, N. I., Kordyum, E. I., \& Guikema, J. A. (2004). Microgravity affects the photosynthetic apparatus of Brassica rapa. Plant Biosystems, $138,1-9$

Li, J., Cang, Z., Jiao, F., Bai, X., Zhang, D., \& Zhai, R. (2015). Influence of drought stress on photosynthetic characteristics and protective enzymes of potato at seedling stage. Journal of the Saudi Society of Agricultural Sciences, 16(1), 82-88.

McElroy, J. S., \& Kopsell, D. A. (2009). Physiological role of carotenoids and other antioxidants in plants and application to turfgrass stress management. New Zealand Journal of Crop and Horticultural Science, 37(4), 327-333.

Moreno-Villanueva, M., Wong, M., \& Wu, H. (2017). Interplay of space radiation and microgravity in DNA damage and DNA damage response. npj Microgravity, 3,14 .

Muthukumar, T., \& Shenbagam, M. (2017). Vegetative anatomical adaptations of Epidendrum radicans (Epidendroideae, Orchidaceae) to epiphytic conditions of growth. Modern Phytomorphology, 11, 117-130.

Oluwafemi, F. A., \& Olubiyi, R. A. (2019). Investigation of corn seeds growth under simulated microgravity. Arid Zone Journal of Engineering, Technology and Environment, 15, 110-115. 
Ovchinnikov, Y. A. (1974). Novye metody analisa aminokislot, peptidov, proteinov [New methods of analysis of aminoacids, peptides, proteins]. Mir, Moscow (in Russian).

Paul, A.-L., Sing, N. J., Zupanska, A. K., Krishnamurthy, A., Schultz, E. R., \& Ferl, R. J. (2017). Genetic dissection of the Arabidopsis spaceflight transcriptome: Are some responses dispensable for the physiological adaptation of plants to spaceflight? PLoS One, 12(6), e0180186.

Pratelli, R., \& Pilot, G. (2014). Regulation of amino acid metabolic enzymes and transporters in plants. Journal of Experimental Botany, 65, 5535-5556.

Sadak, S. H. M., Abdelhamid, M. T., \& Schmidhalter, U. (2015). Effect of foliar application of aminoacids on plant yield and physiological parameters in bean plants irrigated with seawater. Acta Biologica Colombiana, 20(1), 141-152.

Scandalios, J. G. (1993). Oxygen stress and superoxide dismutases. Plant Physiology, 101(1), 7-12.

Sharma, S. S., \& Dietz, K. J. (2009). Review. The relationship between metal toxicity and cellular redox imbalance. Trends in Plant Science, 14(1), 43-50.

Soliman, M. H., Alayafi, A. A. M., El Kelish, A. A., \& Abu-Elsaoud, A. M. (2018), Acetylsalicylic acid enhance tolerance of Phaseolus vulgaris L. to chilling stress, improving photosynthesis, antioxidants and expression of cold stress responsive genes. Botanical Studies, 59(1), 6 .

Stutte, G. W., Monje, O., HatWeld, R. D., Paul, A.-L., Ferl, R. J., \& Simone, C. G. (2006). Microgravity effects on leaf morphology, cell structure, carbon metabolism and mRNA expression of dwarf wheat. Planta, 224, 1038-1049.

Tang, W., \& Newton, R. (2005). Polyamines reduce salt-induced oxidative damage by increasing the activities of antioxidant enzymes and decreasing lipid peroxidation in Virginia pine. Plant Growth Regulation, 46, 31-43.

Tay, S., He, J., \& Yam, T. W. (2019). CAM plasticity in epiphytic tropical orchid species responding to environmental stress. Botanical Studies, 60(7), 1-15.

Wang, H. F., \& Zhan, H. J. (2009). The research progress in determination of catalase activity. Science and Technology Innovation Herald, 19, 7-8.

Weber, H., Chetelat, A., Reymond, P., \& Farmer, E. E. (2004). Selective and powerful stress gene expression in Arabidopsis in response to malondialdehyde. The Plant Journal, 37(6), 877-888.
Wolff, S., Coelho, L., Zabrodina, M., \& Brinckmann, E. (2013). Plant mineral nutrition, gas exchange and photosynthesis in space: A review. Advances in Space Research, 51, 465-475.

Wolff, S., Palma, C., Marcelis, L. F. M., Jost, A.-I., \& van Delden, S. (2018). Testing new concepts for crop cultivation in space: Effects of rooting volume and nitrogen availability. Life, 8(4), 45 .

Wyszkowski, M. (1996). Sklad aminokwsowy bialka bulwczterechodmianziemniaka w zaleznosci od nawozenia azotem. Acta Academiae Agriculturae ac Technicae Olstenensis, Agricultura, 63, 129-138.

Yang, L. Y., Yang, S. L., Li, J. Y., Ma, J. H., Pang, T., Zou, C. M., He, B., \& Gong, M. (2018). Effects of different growth temperatures on growth, development, and plastid pigments metabolism of tobacco (Nicotiana tabacum L.) plants. Botanical Studies, $59,5$.

Zabel, P., Bamseya, M., Schubert, D., \& Tajmar, M. (2016). Review and analysis of over 40 years of space plant growth systems. Life Sciences in Space Research, $10,1-16$.

Zaimenko, N. V. (1999). Effect of clinostating on physiological-biochemical processes in tropical orchids. Ukrainian Botanical Journal, 56(2), 174-179.

Zaimenko, N. V., Didyk, N. P., Ellanska, N. E., Ivanytska, B. O., Pavluchenko, N. A., Rakhmetov, D. B., \& Kharytonova, I. P. (2016). Implementation of new technique for phyto and chemical melioration of acidic and saline soils. Science and Innovation, 12(1), 58-68.

Zaimenko, N. V., Didyk, N. P., Pavliuchenko, N. A., Ivanytska, B. O., Kharytonova, I. P., \& Rositska, N. V. (2018). Natural silicates mixed with organic fertilizers enhance com adaptation to salt stress and improve physical characteristics of sandy soil. Joumal of Crop Improvement, 20, 188-207.

Zhao, Q., Li, J., \& Liu, M. (2002). Effects of simulated microgravity on characteristics of photosynthesis in plant seedling. Space Medicine and Medical Engineering (Beijing), 15(2), 79-83.

Zheng, H. Q., Han, F., \& Le, J. (2015). Higher plants in space: Microgravity perception, response, and adaptation. Microgravity Science and Technology, 27, 377-386. 